\title{
Raising Rates of Childhood Vaccination: The Trade-off Between Coercion and Trust
}

\author{
Bridget Haire • Paul Komesaroff • Rose Leontini • \\ C. Raina MacIntyre
}

Received: 15 May 2017 / Accepted: 2 November 2017 / Published online: 1 March 2018

(C) Journal of Bioethical Inquiry Pty Ltd. 2018

\begin{abstract}
Vaccination is a highly effective public health strategy that provides protection to both individuals and communities from a range of infectious diseases. Governments monitor vaccination rates carefully, as widespread use of a vaccine within a population is required to extend protection to the general population through "herd immunity," which is important for protecting infants who are not yet fully vaccinated and others who are unable to undergo vaccination for medical or other reasons. Australia is unique in employing financial incentives to increase vaccination uptake, mainly in the form of various childcare payments and tax benefits linked to timely, age-appropriate vaccination. Despite relatively high compliance with the childhood vaccination schedule, however, the Australian government has
\end{abstract}

B. Haire $(\bowtie)$

Kirby Institute, Level 6, Wallace Wurth Building, UNSW Sydney, Kensington, NSW 2052, Australia

e-mail: b.haire@unsw.edu.au

P. Komesaroff

Monash Centre for the Study of Ethics in Medicine, Monash

University, Clayton, Australia

e-mail: paul.komesaroff@monash.edu

R. Leontini $\cdot$ C. Raina MacIntyre

School of Public Health and Community Medicine, UNSW

Sydney, Kensington, NSW 2052, Australia

R. Leontini

e-mail: rose.leontini@unsw.edu.au

C. Raina MacIntyre

e-mail: r.macintyre@unsw.edu.au determined that rates should be higher and has recently introduced policy that includes removing certain tax and childcare benefits for non-vaccinators and formally disallowing conscientious objection to vaccination ("No Jab No Pay"). In addition, it has raised the possibility of banning unvaccinated children from childcare centres ("No Jab No Play"). This article examines the impact of coercive approaches to childhood vaccination and raises the question of the ethical justification of health policy initiatives based on coercion. We consider the current evidence regarding childhood vaccination in Australia, the small but real risks associated with vaccination, the ethical requirement for consent for medical procedures, and the potential social harms of targeting non-vaccinators. We conclude that the evidence does not support a move to an increasingly mandatory approach that could only be delivered through paternalistic, coercive clinical practices.

Keywords Childhood vaccination · Ethics · Incentive · Conscientious objection $\cdot$ Public health $\cdot$ Herd immunity

\section{Introduction}

Vaccination is a highly effective public health strategy that provides protection to both individuals and communities from a range of infectious diseases (Ehreth 2003). Complete vaccination coverage is rarely achieved in any population (Schlipköter and Flahault 2010). However, widespread use of a vaccine within a population extends protection to many 
unvaccinated members through "herd immunity." Herd immunity is important for protecting infants who are not yet fully vaccinated and others who are unable to undergo vaccination for medical or other reasons. The vaccine coverage required to achieve herd immunity is disease-specific, being greater for more highly infectious pathogens (Kim, Johnstone, and Loeb 2011). For these reasons, governments need to monitor vaccination rates carefully and to consider intervention in the public interest should rates decline below the required threshold for a particular disease.

Around the world, a variety of inducements are employed to encourage participation in vaccination programmes. These are mainly centred around education, health promotion, and incentives but also include mandatory provisions (Achat, McIntyre, and Burgess 1999). Australia is unique in employing financial incentives to increase participation, mainly in the form of various childcare payments and tax benefits linked to timely, age-appropriate vaccination (Ward, Hull, and Leask 2013). While this approach has resulted in vaccination rates in fifteen-month-old children of greater than 93 percent (Australian Government Department of Health 2017), in 2016 the federal government nonetheless introduced yet another strategy — referred to widely as the "No Jab, No Pay" policy (National Centre for Immunisation Research and Surveillance 2016) — to increase vaccination rates which involved removing certain tax and childcare benefits for non-vaccinators and formally disallowing conscientious objection to vaccination. The government has also raised the possibility of banning unvaccinated children from childcare centres (dubbed "No Jab, No Play"). The stated aim of these strategies is to increase vaccination rates to at least 95 percent.

This article examines the impact of coercive approaches to childhood vaccination such as these and raises the question of the ethical justifiability of health policy initiatives based on coercion.

\section{State and Federal Jurisdictions in Australia}

Australia employs a federal system of government in which the central government takes full responsibility for the welfare system, with the six states and two territory governments assuming responsibility for other major areas including health and education. This gives the federal government the power to make unilateral decisions about welfare spending, while leaving the states and territories to control the regulation of childcare centres in their jurisdictions, including enrolment criteria. In 2016, Australian conscientious objector parents who did not vaccinate their children lost their eligibility for welfare payments, including a family tax supplement, a childcare benefit payment, and a childcare rebate payment, which together can add up to a maximum amount of around $\$ A 15,000$. Medical ineligibility is an approved exemption, and allowances are made for children on an approved catch-up vaccination schedule (Klapdor and Grove 2015). Whereas, previously, conscientious objectors to vaccination could claim these benefits, the new policy only exempts children with a medical contraindication to vaccination.

Several states and territories allow admission of unvaccinated children to childcare, with the provision that they may be excluded during a relevant disease outbreak. Three states (Victoria, New South Wales, and Queensland) require children to be fully immunized to enrol in childcare in the absence of a medical contraindication or participation in an approved catch-up programme. In New South Wales alone, registration as a conscientious objector to vaccination allows a child to enrol in childcare, so long as the parents participate in a formal process of registering the objection, which includes a conversation with a healthcare provider. In all states, unimmunized children are excluded during disease outbreaks, regardless of the reason for non-vaccination.

This patchwork of sometimes contradictory requirements across the jurisdictions is one of the targets of the new federal initiative, which aims to achieve uniform legislation that both excludes unvaccinated children from childcare and disallows the possibility of exemption related to conscientious objection (National Centre for Immunisation Research and Surveillance 2016).

\section{Moral Responsibilities of Individuals and Governments}

In what follows, our discussion is not intended to discount the important role of the state in achieving the aims of public health (including policies to increase vaccination rates). Nor do we wish to suggest that health 
in a liberal democracy ought to be left entirely up to individuals' self-regulation and unlimited choice. However, we believe it is worth considering the implications of coercive approaches to childhood immunization in the Australian context, where vaccination rates are reasonably high. The questions are whether the imposition of coercive measures is justified, and whether these would be successful in achieving the aim of higher immunization rates without unexpected and/or higher levels of harms.

Some commentators have argued that there is a "duty" to submit to vaccination (Carson and Flood 2017; McCartney 2017) and that failure to do so encumbers the individuals concerned with moral responsibility for any harms that may follow (Jamrozik, Handfield, and Selgelid 2016). It is possible that some parents might be persuaded by such an argument and subsequently agree to allow their children to be vaccinated. However, there is no obvious link between a supposed "moral responsibility" and justification of measures instigated by government to enforce compliance with treatment. In addition, coercive measures are likely to provoke negative responses by both practitioners and community members, as well as exacerbate the isolation of unvaccinated people. We will return to these points shortly.

In modern liberal democracies, government intervention in parenting is largely limited to prevention of, and responses to, child abuse and neglect, with actions mandated where risk is deemed high (McIntyre, Williams, and Leask 2003). In Australia, because of the herd immunity effect, the high background levels of vaccination mean that opting not to vaccinate a child is unlikely, in the normal course of events, to expose that child to high risk. Measles requires herd immunity of 95 per cent, but measles epidemics in Australia are usually imported through travel and sustained by pockets of under-vaccinated adults and older children not covered by the new policy (MacIntryre et al. 2016). While benefiting from the fact that others are vaccinated without being vaccinated oneself may be deemed by some to be unfair (and even as "freeloading"), with adequate population coverage the presence of a small unvaccinated minority does not pose significant dangers.

The wide community acceptance of certain public health policies that enforce compliance through legislation, such as the wearing of seat belts in cars or helmets while riding bicycles, may be cited in support of the use of coercion. However, while it is true that these policies are accepted, the requirement to wear a seat belt or a helmet differs from compulsory vaccination in several important respects. First, helmets and seat belts cannot, under ordinary circumstances, themselves cause injury. Even though some evidence suggests that helmet wearing occasionally leads to increased risk-taking behaviour (Gamble and Walker 2016), the occurrence of a risk event requires an external event - an "accident"- to occur. If such an event does occur, helmets and seat belts overwhelmingly reduce injury and death. This is different to vaccines, which can sometimes cause serious adverse effects in their own right. Second, the use of helmets and the use of seat belts are not medical interventions and do not involve invasive intrusions into the bodies of individual citizens, as is the case with vaccines, which require informed medical consent. Third, helmets and seat belts do not require the participation of other persons - such as health professionals - who become implicated in the imposition of coercive measures and the undermining of accepted standards and values of clinical practice.

\section{Overriding Consent to Medical Treatments}

The Australian Immunisation Handbook states that vaccination should only be given in the presence of valid informed consent and that consent "must be given voluntarily in the absence of undue pressure, coercion or manipulation" (Australian Government 2013, revised 2017). Although precise details vary, respect for the rights of individual patients to provide or decline consent to medical treatments is a fundamental precept of contemporary Western societies which has emerged out of both their ethical and their legal traditions. The exceptions to such rights are few and are largely limited to circumstances in which an individual, or the person who has legal responsibility for an individual, is unable to make a clear and informed decision: for example, in psychosis, dementia, or emergencies where consent cannot be obtained. There are also state-based Public Health Acts which can be used to override the rights of individuals if the safety of the public is at risk (NSW Government 2010). This has been amended in New South Wales to include collection of immunization data on children and to allow exclusion from childcare in the event of an outbreak (Fraser et al. 2016). There are some additional, rare circumstances in which the courts may be called upon to 
provide authority for practitioners to act- such as disputes between doctors and parents about the treatment of children with serious illnesses-but these are always considered individually in relation to the merits of individual cases. There are no circumstances apart from those involving vaccinations in which mass compulsory medical treatment has been contemplated. At the very least, overriding or dispensing with consent should be regarded as a major step with significant risks, which should only be undertaken in extreme circumstances where no alternatives are possible.

Undermining respect for the principle that medical treatments require valid processes of consent could pose significant dangers, one of these being a counterproductive resistance to a public health programme. Resistance is often related to perceptions that the state is interfering with individual liberty. This is not a new phenomenon; resistance by parents toward childhood vaccinations dates back to the nineteenth century (Reynolds 2011, 306). When the state passes legislation that excludes benefits for tax-paying citizens (for example financial incentives or even access to childcare centres) this perception is crystallized, potentially leading to an erosion of trust by the community in the medical profession and public agencies. Trust is important because people are more likely to be "educated" by a person with whom they have an existing therapeutic relationship, rather than from institutions or anonymous public health officials.

In addition, coercive measures could lead to the creation of a class of individuals who feel alienated from the rest of society, as well as contribute to the establishment of a principle that could be extended to other, potentially even more problematic, conditions. From a deontological perspective, a public health initiative that, directly or indirectly, isolates or stigmatizes a population group on the basis of their behaviour is unethical because it attacks the "worth" of that group and because it has the power to manipulate the opinions of the public towards that group (Dean 2014). The refusal to treat families by some doctors who have a poor opinion of parents who object to vaccination (see Omar et al. 2009), for example, amounts to another form of coercion, in this case on behalf of a healthcare professional who is perceived as having the power to withdraw care or, alternatively, to influence unduly the healthcare decisions of parents. This attitude does not improve immunization rates and increases the risk of losing trust in healthcare and vaccination.

These risks have been well recognized by medical professional organizations - such as the Australian Medical Association-which have advised medical practitioners not to participate in immunization if the parent feels coerced (AMA 2016). Such a lack of cooperation by medical professionals, afraid of breaching valid informed consent to a medical procedure, would in itself be a further undesirable consequence that could have additional adverse ramifications for the implementation of public health policies.

\section{Vaccine Risks}

Serious adverse reactions to vaccines are very rare, with rates varying with the vaccines used. For example, the incidence of such reactions with measles is one in a million, while for the oral polio vaccine it is one in 750,000 for the first dose, reducing to one in 2-3 million doses thereafter (CDC 2011). Of note, the risk of death from measles is estimated at one in a thousand (Orenstein et al. 2004), and one in two hundred who contract polio will experience irreversible paralysis (WHO 2017), so it is clear that the risk of a vaccine reaction is much lower than the risks posed by vaccine preventable diseases. However, despite the rarity of serious vaccine reactions, they do occasionally occur, and the harms caused can be severe. In addition to the low observed rate of serious adverse events in routine vaccine use, historically there have been some catastrophic unanticipated vaccine safety issues.

Famously, the Cutter polio incident in 1955 involved a contaminated batch of Salk vaccine causing polio infection in 40,000 school children. An error had occurred in the manufacture of the vaccine, as a result of which, instead of being vaccinated with an inactivated virus, the children were injected with live polio virus. Fifty-one children were paralyzed and five died, with a further 113 family members of the school students contracting polio, of whom five also died (Offit 2005).

Clinical trials are often insufficiently powered to detect rare adverse events. The trials of the first rotavirus vaccine, RotaShield, delivered to U.S. infants provide an example of this (Murphy et al. 2001). When more data ultimately became available in 1999-by which time 13 percent of U.S. infants had received it - the vaccine was withdrawn because 
of an unacceptable risk of intussusception and one death (CDC 2011; Miller et al. 2015).

Issues with vaccine safety continue to occur. In 2010 an influenza vaccine programme in Western Australia was suspended for children under the age of five after twenty-three children had been admitted to hospital with febrile convulsions following immunization. The case was investigated by the Therapeutic Goods Administration and the association confirmed (Australian Government Department of Health TGA 2010), and this reactogenic vaccine is now contraindicated for children. According to Wood et al., "The method of manufacture of the Fluvax vaccine, which unknowingly preserved strain-specific viral components of new influenza strains in 2010, appears to have been responsible for the higher rate of fever in children" (Wood et al. 2014, 596).

The above examples demonstrate that concerns about the risks associated with vaccination should not be dismissed as unreasonable and that vaccine programmes must be delivered with full transparency about the possibility of unexpected serious adverse events. Whether in a particular case the overall benefit to a population justifies a small level of risk to individuals must be decided on the basis of a risk-benefit analysis, which includes both factual and ethical considerations. In settings where the dangers posed by a given infection are very high, mild to moderate adverse events may be tolerated. However, even in more extreme circumstances tolerance of serious adverse events is usually low. Coercive policies could undermine trust in vaccine programmes should unanticipated adverse events occur.

The assessment of risks and benefits may vary with the disease burden. For example, the serious adverse event profile of smallpox vaccine is considerable but when the disease remained endemic the risks were considered to be ethically justifiable. As the disease became rarer, however, the view gradually formed that the risk of vaccination outweighed the benefits, especially in countries such as the United States where cases were no longer occurring (Lane et al. 1969).

Of course, even where there is a broad consensus among public authorities that the dangers of a disease justify the risks associated with vaccination, when an individual experiences an adverse event the harms are no longer hypothetical but tangible and real. In these cases, furthermore, the harms created may extend far beyond the injury to the affected individual. The combination of a large-scale safety problem (such as the Cutter incident) and a coercive policy may seriously damage trust in the integrity of the medical system in general and the public health system in particular.

The requirement of consent as a basic condition of medical treatment is not a mere cultural preference: it is a condition of possibility for the viability of the healthcare system. Where the full details of a treatment have been openly and transparently discussed with a patient-including the risks and potential benefits to themselves and others, no matter how unlikely-and a free and uncoerced decision is made to proceed, it is possible to accept whatever ensues without calling into question the integrity of the professional relationship, the authority of the public authorities, or of caring relationships in general. Where governments mandate certain treatments and override the capacity of individuals to make decisions about their own welfare or those of their children all of these basic assumptions may be put at risk.

These concerns are exacerbated in those settings — such as Australia - where little or no public compensation is available in cases of injury. Whereas in the United States "no fault" compensation legislation ensures that individuals who suffer from serious vaccine-associated adverse events receive compensation without having to prove that the manufacturer was at fault (Looker and Kelly 2011), this is not the case in Australia. This undoubtedly adds to the risks of policies based on coercion.

Taken together, these considerations lead to the conclusion that the risks of vaccination-even if small-increase the need for valid, freely given consent to be obtained from individuals participating in vaccine programmes, either on their own behalf or on behalf of their children.

\section{The "No Jab, No Pay" / "No Jab, No Play" Policies}

The Australian policy of withholding particular financial benefits from non-vaccinators was introduced nationwide in 2016 (as previously mentioned, because the federal government controls welfare payments this policy could be rolled out simultaneously across the country) (Klapdor and Grove 2015). Since that time, government spokespersons have reported that vaccination rates have increased around three per cent (Doran 2017). While an overall increase is undoubtedly welcome, it is, however, worth reflecting both on the evidence 
regarding the circumstances of non-vaccinators in Australia, the likely social outcomes, and the ethics of imposing welfare penalties for non-vaccination.

Unintended consequences of Victoria's "No Jab, No Play" policy have been recently exposed in the media, with reports of anti-vaccination parents seeking out a fringe medical practitioner who was willing to sign medical ineligibility forms fraudulently (Choahan 2017). This practice has at least three negative effects: it encourages some medical practitioners who are sympathetic to anti-vaccinators for whatever reason to commit fraud; it further cements a politicized collective identity for anti-vaccinators that might further distance these people from effective mainstream medicine; and finally, it defeats the aim of the policy, to increase vaccination uptake.

In response to media outrage about the conduct of the medical practitioner involved, Australian experts in vaccination policy noted that retaining non-medical exemptions that require ongoing conversation with doctors would be preferable, in order to keep anti-vaccinators in a relationship with mainstream medicine, to prevent seeking out of fringe practitioners, and to avoid pressure for doctors to commit fraud (ABC 2017, Johnson 2017).

In 2016, a study of the geographic and demographic trends in objection to vaccination in Australia found an increase in objection from 1.1 per cent of the population in 2002 to 2 per cent in 2013 (Beard et al. 2016). The study found a clustering of vaccine objection in regional areas. Registered vaccine objection was lower in the lowest socio-economic decile (1.1 percent) than in the highest (1.9 percent). Conversely, partial vaccination without a registered objection was highest in the lowest socio-economic decile (5 vs 3 ). Incomplete vaccination without a registered objection suggests that some parents may encounter structural barriers to vaccinating children (Beard et al. 2016).

These facts point to two important implications, both to do with equity. First, the wide prevalence of partial immunization among vaccine objectors' children suggests a reasoned response to particular vaccines rather than a blanket refusal of all of them. In turn, this suggests that these parents are not "freeloaders" but rather genuinely concerned individuals who negotiate the risks and benefits of different types of vaccines, giving consideration to possible harms as well as social responsibilities. Second, the evidence suggests that many members of population groups from disadvantaged backgrounds face structural barriers to healthcare services possibly relating to educational resources (formal and informal) as well as to biomedical care. If this is indeed the case, withdrawal of welfare benefits will likely exacerbate such disadvantage. Further, because registered vaccine objectors tend to reside in the best socio-economically resourced postcodes (Leask and Danchin 2017) and are therefore unlikely to be eligible for the family tax benefit and childcare benefit payments, the "no pay" policy will disproportionately impact on poorer families who already face structural barriers to vaccination.

If vaccine access is an issue, then the duty of the state is to ensure that the barriers to access be removed in order to protect children from potentially lifethreatening disease, families from potential stigma and inequity, and communities from potential outbreaks and associated costs. This is a different approach to one that presumes children ought to be protected from (the presumed) neglect or harm by their parents. The latter assumption fosters further suspicion and mistrust among parents whereby they would perceive the establishment (both public health and medical) as adopting an adversarial view that pitches the needs of the child against the concerns of the parents.

Prohibition of the enrolment of unvaccinated children in childcare is likely to worsen both health and social disadvantage and inequalities and will have a disproportionate impact on women. Those most likely to be affected are the most vulnerable, such as poorer working women, whose chances of joining or returning to the workforce will be reduced (MacIntyre 2017). The social isolation and stigmatization of both mothers and children are likely to produce ongoing harmful effects for all involved, extending from developmental implications for the children to financial hardship and psychological damage to the mothers. It is likely that the alienation of non-vaccinating families will extend beyond the single procedure of vaccination to exclusion from healthcare services more broadly, with resulting damage both to the families involved and the wider community. Reports of medical care being withheld from non-vaccinators have already emerged in Australia (Noonan 2017).

"No Jab, No Play" may, therefore, generate many harmful effects. But what will be the benefits? Unfortunately, evidence for benefit is lacking. There is no evidence that marginal increases in vaccination rates from 
vaccine-hesitant parents will prevent an outbreak of infectious disease more effectively than the existing policy of excluding unvaccinated children during outbreaks. In terms of disease control, there is no evidence that unvaccinated children of objectors are the major risk group. Recurrent measles epidemics in Australia, for example, have seen calls for more punitive measures against objecting parents. However, a study of measles cases showed that only 14 per cent of cases were in children of objectors, and most cases occurred in other risk groups and across all ages (MacIntyre et al. 2016). In this case, "No Jab, No Pay" would not have any impact on over 80 per cent of measles cases. In other words, what research is available does not provide a justification for a policy that is likely to produce deep inequities among population groups in Australia.

Second, the policies can actually backfire in terms of health education and dialogue in the community. The success rates of public health interventions that rely on health promotion messaging alone are, at best, difficult to prove, and at worst they reinforce the suspicions and negative opinions held by those with a strong antivaccination stance (Bester 2015). Similarly, Omar et al. (2009) underline the importance of healthcare professionals in shaping parents' decisions on vaccination, because they are in the best position to make recommendations, tailoring education and information to the family's needs, background, and context, engendering trust and providing reassurance regarding any perceived and actual risks. It is worth noting, on this point, that education is not just for parents and the community but also for physicians on how to understand and address the different views and concerns of parents and develop good communication skills that help them inform parents and build trust. Information or "education" is in this sense understood as being both tailored to the particular social location of parents, as well as to the context and types of concerns. In any case, for these scholars, the best placed people for educating parents are physicians. If this is the case, we cannot use physicians to impose coercive measures that would alienate their patients in an attempt to fulfil the greatest public "good" for the greatest number. While physicians are in many ways agents of public health, they are also providers of primary care to families.

The impetus from the federal government to achieve a nationwide consistent policy regarding vaccination and childcare enrolment includes pressure to remove the exemption for registered, bona fide conscientious objectors that exists in Australia's most populous state, New South Wales. Currently, registration as a conscientious objector entails four steps: the parent filling out a form, having it co-signed by a general practitioner, lodging it with Medicare, and providing a copy to the childcare centre. This process ensures that nonvaccination involves a deliberate, considered choice which has been discussed between the parent and a healthcare provider. In addition to undermining the rights of parents to make the decisions they consider most appropriate for their children, removal of the possibility of conscientious objection will therefore also eliminate a step that often allows for parents to be persuaded in favour of vaccination - or perhaps to be convinced to vaccinate their child or children with some but not all vaccines on the immunization schedule.

Third, the exclusion of children from childcare centres could produce yet another, even more undesirable, outcome: the establishment of childcare centres specifically for children who are not vaccinated at all or only partially. Such a high concentration of unvaccinated children would be especially dangerous because, in the complete absence of a "herd immunity" effect, all the children - and their contacts - would be highly vulnerable. It is possible that this outcome would not only lead to an increase in the risk of epidemics and the overall prevalence of certain infectious diseases but would also increase the disability associated with them.

Implementation of a "No Jab, No Pay/Play" policy may therefore be counterproductive and increase the risk of multiple harmful outcomes without demonstrable benefits. Other countries such as Canada achieve high rates of vaccination without any legislation, and there are many proven strategies which successfully raise vaccination rates without coercion (Salmon, MacIntyre, and Omer 2015). Such strategies include increasing administrative hurdles for conscientious objection, removing barriers to timely immunization, and providing decision support to parents.

\section{Non-Vaccinators Among Population Groups}

Much of the concern about vaccination rates in Australia centres on geographic pockets that have higher rates of non-vaccination than the general population (the New South Wales town of Lismore is the example offered by Danchin and Nolan 2014). As the risks of infectious disease outbreaks are highest in such communities, they 
are sometimes presented as requiring coercive strategies to bring them into line (for example, see Billias 2016). In addition to those mentioned above, pockets of undervaccination include migrant groups which are not captured in the childhood immunization register. For example, the largest epidemic of measles since 1997 occurred in Australia in 2012, and it was found that undervaccinated young adults of migrant origin were a large risk group (Najjar et al. 2014).

The argument that vaccination should be a "nonnegotiable legal obligation" imposed on parents rather than left to parental choice is advanced by Pierik (2016, 1). In his view, as vaccination is both a private and a collective good, our rights and obligations must reflect this dual nature and distribution of "good" and of the burdens and benefits that immunization brings. In addition, notes Pierik, vaccine objectors are an increasingly organized group that uses a variety of media to propagate concerns and perhaps misinformation about the risks and benefits of immunization (Pierik 2016). Fuelled by a more deliberate distrust in the scientific and medical establishments, they broaden their reach in spite of the significant evidence base and rigorous peer review of biomedical research and technologies. While this is an important point, we suggest that if such distrust in scientific and medical technologies already exists among some population groups, then coercive measures will only reinforce this mistrust by broadening it to include the physicians and public health initiatives that they may otherwise consider acceptable. Indeed, such mistrust could be further fuelled by a perception of a state and medical alliance designed to undermine the principle of autonomy.

Similarly, Sheather (2013) argues that the parental right to make decisions on behalf of children is not absolute; legally, children have also the right to seek protection. For Sheather, this issue needs to be considered in relation to the child's welfare ("the welfare decision"). It should also be considered in relation to the public good ("harm to others") in which a nonimmunized child is taken also as a potential vector of disease. However, unlike Pierik, Sheather considers legal sanctions imposed on parents "extreme" and often ineffective, suggesting instead that a more appropriate approach can be through education and incentives. In a similar vein, and echoing much of the literature, Danchin and Nolan (2014) note that vaccine hesitancy and refusal usually reflect a problem of trust in the medical and scientific establishment. Thus, while views differ among scholars as to the degree of interference or coercion the state ought to have on child immunization, a common theme among them is that persuasion and education should prevail first and foremost and should only be overruled by paternalism or compulsion in the extreme circumstances in which these approaches do not work and where time constraints could pose a real threat to the child and/or society.

Current policies directed at objecting parents of infants are unlikely to address the issues facing these specific cultural groups. Rather, the approaches most likely to be effective are those that work to build rapport, empathy, and trust between healthcare providers and members of vaccine hesitant or resistant communities. Working from earlier Australian research detailing mothers' decision-making about vaccines (Benin et al. 2006) and using categories defined by Leask et al. (2012), Danchin and Nolan (2014) propose a nuanced approach to communicating with parents about vaccines and, in the case of vaccine refusers, setting goals that fall short of full vaccine acceptance. From the evidence available, such an approach would seem to be more likely to succeed than one based primarily on coercion.

While coordinated strategies to improve education and communication may not produce a rapid elimination of all resistance to vaccination, it is likely that they would generate more sustainable, enduring solutions that avoid harsh outcomes, resentment, and more extensive social damage.

\section{Public Health Ethics and Coercion}

While there are different accounts of public health ethics, a common identified tension is the need to balance the value of the freedom of individuals against the interests of the wider community (Upshur 2002). This is directly relevant to the subject of vaccination, where there is clearly a common interest for the vast majority of the population to be vaccinated in order to achieve sufficient individual and herd immunity. However, the assessment of how far it is appropriate for a government to go to achieve particular goals involves a wide range of considerations, including the relevant factual circumstances, the cultural composition of the community, the different values held by its members, the educational and economic conditions, and the 
processes that exist within the society for the resolution of ethical differences.

Accounts of public health ethics that privilege autonomy indicate that elevated levels of government intervention are only justified where the threat of the disease to the population is sufficiently serious (Nuffield Council on Bioethics 2007). In other words, if the disease threat is small and can be managed by less coercive means, it should be. Alternatives to restrictive policies are those that enable choice through structural means, such as education and enabling positive choice through programmes that reduce barriers (Griffiths and West 2015) or increasing administrative barriers for objection (Salmon, MacIntyre, and Omer 2015)

Finally, the imposition of new coercive policies in Australia needs to be seen in the current context in which deliberate non-vaccination for reasons of conscience is not in fact increasing. For this reason alone, it is likely that the negative effects of the penalties and disincentives will be experienced primarily by people who fail to vaccinate for logistical reasons and who may have benefited most from more supportive, enabling approaches.

\section{Conclusion}

The control of infectious diseases is often raised as an example of where the coercive powers of the state may be justly exercised at the expense of individual freedom. However, coercive measures can be justified only if they are the sole, or incontestably the most effective, way to achieve the outcome, and if the benefits associated with this outcome outweigh the social damage thereby produced.

In Australia, vaccination rates are high and stable. The evidence shows that many parents whose children are incompletely vaccinated have failed to complete the programme for structural rather than ideological reasons (Beard et al. 2016). Effective protection is provided for both vaccinated and unvaccinated children in the event of outbreaks of vaccinepreventable infections by clear back-up policies.

We conclude that the evidence does not support a move to an increasingly mandatory approach that requires paternalistic, coercive practices. Approaches are available that tighten procedures for registering objection while simultaneously enhancing consumer autonomy, improving access to healthcare, and removing barriers to information and vaccination. Such approaches are preferable to ensure adequate protection for the community while avoiding the risks and potential negative social effects of punitive policies.

\section{References}

ABC News. 2017. Interview with Julie Leask. https://witter. com/abcnews/status/900631038631714816?s=09. Accessed September 4, 2017.

Achat, H., P. McIntyre, and M. Burgess. 1999. Healthcare incentives in immunisation. Australian and New Zealand Journal of Public Health 23(3): 285-288.

Australian Government Department of Health. 2017. Immunise Australia program: AIR current data. http://www.immunise. health.gov.au/internet/immunise/publishing. nsf/Content/acir-curr-data.htm. Accessed September 4, 2017.

Australian Government Department of Health. 2013 revised 2017. The Australian immunisation handbook 10th ed. http://www. immunise.health.gov.au/internet/immunise/publishing. nsf/Content/Handbook10-home $\sim$ handbook10part2 handbook10-2-1\#2-1-3. Accessed April 26, 2017.

Australian Government Department of Health Therapeutic Goods Administration (TGA). 2010. Seasonal flu vaccine: Investigation into febrile reactions in your children following 2010 seasonal trivalent influenza vaccination. https://www. tga.gov.au/alert/seasonal-flu-vaccine-investigation-febrilereactions-young-children-following-2010-seasonal-trivalentinfluenza-vaccination. Accessed April 6, 2017.

Australian Medical Association (AMA). 2016. Update on antivaccination ploy to avoid "no jab no pay" laws. https://ama. com.au/gp-network-news/update-anti-vaccination-ployavoid-percentE2percent80percent98no-jab-no-paypercentE2 percent80percent99-laws Accessed April 26, 2017.

Beard, F.J., B.P. Hull, J. Leask, A. Dey, and P.B. McIntyre. 2016. Trends and patterns in vaccination objection, Australia, 2002-2013. Medical Journal of Australia 204(7): 275.

Benin, A.L., D.J. Wisler-Scher. E. Colson, E.D. Shapiro, and E.S. Holmboe. 2006. Qualitative analysis of mothers' decisionmaking about vaccines for infants: The importance of trust. Pediatrics 117(5): 1532-1541.

Bester, J.C. 2015. Vaccine refusal and trust: The trouble with coercion and education and suggestions for a cure. Journal of Bioethical Inquiry 12(4): 555-559.

Billias, M. 2016. Refusing to vaccinate is akin to child abuse. Daily Telegraph, Feb 27. http://www.dailytelegraph.com. au/rendezview/parents-who-dont-vaccinate-their-kids-arechild-abusers/news-story/a1f7b270b76123ffa 7cbba7e25 ded4b8. Accessed May 15, 2017.

Carson, P.J., and A.T. Flood. 2017. Catholic social teaching and the duty to vaccinate. The American Journal of Bioethics 17(4): $36-43$.

Centres for Disease Control and Prevention (CDC). 2011. Rotavirus vaccine (RotaShield) and intussusception. https://www.cdc.gov/vaccines/vpd-vac/rotavirus/vacrotashield-historical.htm. Accessed 26 April, 2017. 
Centers for Disease Control and Prevention (CDC). 2015. Guillain-Barré syndrome and flu vaccine. https://www. cdc.gov/flu/protect/vaccine/guillainbarre.htm. Accessed April 5, 2017.

Choahan, N. 2017. Anti-vax Melbourne GP John Piesse faces suspension by medical regulator. The Age, August 24. http://www.theage.com.au/victoria/antivax-melbourne-gpjohn-piesse-faces-suspension-by-medical-regulator20170824-gy30qt.html. Accessed September 2, 2017.

Danchin, M., and T. Nolan. 2014. A positive approach to parents with concerns about vaccination for the family physician. Australian Family Physician 43(10): 690-694.

Dean, R. 2014. Stigmatization and denormalization as public health policies: Some Kantian thoughts. Bioethics 28(8): 414-419.

Doran, M. 2017. Vaccination rates in children up since "no jab, no pay" introduced, federal government says. ABC News Online, July 31. http:/www.abc.net.au/news/2016-07-31/government-labels-nojab,-no-pay-policy-a-success/7675172 Accessed April 5, 2017.

Ehreth, J. 2003. The value of vaccination: A global perspective. Vaccine 21(27-30): 4105-4117.

Fraser A., S. Williams, S. Kong, L. Wells, L. Goodall, S. Pit, et al. 2016. Public Health Amendment (Vaccination of Children Attending Child Care Facilities) Act 2013: Its impact in the Northern Rivers, NSW. Public Health Research \& Practice.

Gamble, T., and I. Walker. 2016. Wearing a bicycle helmet can increase risk taking and sensation seeking in adults. Psychological Science 27(2): 289-294.

Griffiths, P.E., and C. West. 2015. A balanced intervention ladder: Promoting autonomy through public health action. Public Health 129(8): 1092-1098.

Jamrozik, E., T. Handfield, and M.J. Selgelid. 2016. Victims, vectors and villains: Are those who opt out of vaccination morally responsible for the deaths of others? Journal of Medical Ethics 42(12). doi:https://doi.org/10.1136 /medethics-2015-103327.

Johnson, R. 2017. Experts speak out about Melbourne's anti-vax doctors. Gizmodo, August 25. https://www.gizmodo.com. au/2017/08/experts-speak-out-about-melbournes-anti-vaxdoctors. Accessed September 4, 2017.

Kim, T.H., J. Johnstone, and M. Loeb. 2011. Vaccine herd effect. Scandinavian Journal of Infectious Diseases 43(9): 683-689.

Klapdor, M., and A. Grove. 2015. "No Jab No Pay" and other immunisation measures. http://www.aph.gov.au/About_ Parliament/Parliamentary_Departments/Parliamentary_ Library/pubs/rp/BudgetReview201516/Vaccination. Accessed April 5, 2017.

Lane, J. M., F.L. Ruben, J.M. Neff, and J.D. Millar. 1969. Complications of smallpox vaccination, 1968. New England Journal of Medicine 28(22): 1201-1208.

Leask, J., and M. Danchin. 2017. Imposing penalties for vaccine rejection requires strong scrutiny. Journal of Paediatrics and Child Health 53(5): 439-444.

Leask, J., P. Kinnersley, C. Jackson, F. Cheater, H. Bedford, and G. Rowles. 2012. Communicating with parents about vaccination: A framework for health professionals. BMC Pediatrics 12(1): 154.

Looker C., and H. Kelly. 2011. No-fault compensation following adverse events attributed to vaccination: A review of international programmes. Bulletin of the World Health Organization 89(5): 371-378.
McCartney, J.J. 2017. The duty to vaccinate: Clarifying and broadening the basis of the obligation. The American Journal of Bioethics 17(4): 46-47.

MacIntyre, C.R. 2017. Banning unvaccinated kids from child care may have unforeseen consequences. The Conversation, March 14. https://theconversation.com/banningunvaccinated-kids-from-child-care-may-have-unforeseenconsequences-74437. Accessed May 15, 2017.

MacIntyre, C.R., S. Karki, M. Sheikh, N. Zwar, and A.E. Heywood. 2016. The role of travel in measles outbreaks in Australia-An enhanced surveillance study. Vaccine 34(37): 4386-4391.

McIntyre P., A. Williams, and J. Leask. 2003. Refusal of parents to vaccinate: Dereliction of duty or legitimate personal choice? Medical Journal of Australia 178(4): 150-151.

Miller, E.R., P.L. Moro, M. Cano, and T.T. Shimabukuro. 2015. Deaths following vaccination: What does the evidence show? Vaccine 33(29): 3288-3292.

Murphy, T.V., P.M. Gargiullo, S. Mehran. D.B. Massoudi, A.O. Nelson, C.A. Jumaan, et al. 2001. Intussusception among infants given an oral rotavirus vaccine. New England Journal of Medicine 34 (8): 564-572.

Najjar Z., H. Kirsty, P. Clark, O. Nguyen, A. Rosewell, and S. Conaty. 2014. Sustained outbreak of measles in New South Wales, 2012: Risks for measles elimination in Australia. Western Pacific Surveillance and Response Journal 5(1): 14.

National Centre for Immunisation Research and Surveillance. 2016. No jab no pay, no jab no play policies. http://www. ncirs.edu.au/consumer-resources/no-jab-no-play-no-jab-nopay-policies Accessed April 5, 2017.

New South Wales Government. 2010. Public Health Act 2010. http://www.health.nsw.gov.au/phact/Pages/default.aspx. Accessed April 5, 2017

Noonan, A. 2017. Unvaccinated Australian children being refused medical care over immunisation, survey finds. $A B C$ news. http://www.abc.net.au/news/2017-03-08/children-withoutvaccinations-being-refused-medical-care:-study/8334666 March 8. Accessed April 28, 2017.

Nuffield Council on Bioethics. 2007. Public health: Ethical issues. London: Nuffield Council on Bioethics. https://nuffieldbioethics.org/wp-content/uploads/2014/07 /Public-health-ethical-issues.pdf. Accessed April 5, 2017.

Offit, P. A. 2005. The Cutter incident, 50 years later. The New England Journal of Medicine 352(14): 1411-1412.

Omer, S.B., D.A. Salmon, W.A. Orenstein, M.P. deHart, and N. Halsey. 2009. Vaccine refusal, mandatory immunization, and the risks of vaccine-preventable diseases. The New England Journal of Medicine 360(19): 1981-1988.

Orenstein, W.A., R.T. Perry, and N.A. Halsey. 2004. The clinical significance of measles: A review. The Journal of Infectious Diseases 189 (S1): S4-S16.

Pierik, R. 2016. Mandatory vaccination: An unqualified defence. Journal of Applied Philosophy. doi:https://doi.org/10.1111 /japp. 12215

Reynolds, C. 2011. Public and environmental health law. Sydney: The Federation Press.

Salmon D.A., C.R. MacIntyre, and S.B. Omer. 2015. Making mandatory vaccination truly compulsory: Well intentioned but ill conceived. The Lancet Infectious Diseases 15(8): 872-873. 
Schlipköter, U., and A. Flahault. 2010. Communicable diseases: Achievements and challenges for public health. Public Health Reviews 32(1): 90-119.

Sheather, J. 2013. Should childhood MMR vaccination be compulsory? Rights, duties and the public interest. Human Vaccines \& Immunotherapeutics 9(6): 13891391.

Upshur, R.E.G. 2002. Principles for the justification of public health intervention. Canadian Journal of Public Health 93(2): 101-103.
Ward K., B.P. Hull, and J. Leask. 2013. Financial incentives for childhood immunisation - a unique but changing Australian initiative. Medical Journal of Australia 198(11): 590-592.

World Health Organization (WHO). 2017. Poliomyelitis Fact Sheet. Updated April 2017. http://www.who. int/mediacentre/factsheets/fs114/en. Accessed April 5, 2017.

Wood N.J., C.C. Blyth, G.A. Willis, P. Richmond, M.S. Gold, J.P. Buttery, et al. 2014. The safety of seasonal influenza vaccines in Australian children in 2013. Medical Journal of Australia. 201(10): 596-600. 